\title{
Hydraulic function of the kasumi levee system on the Kurobe Alluvial Fan of the 19th century
}

\author{
Hiroshi SENOO $^{1}$ and Tadaharu ISHIKAWA ${ }^{2}$ \\ ${ }^{1}$ TOKEN C. E. E. Consultants Co., Ltd., Tokyo, 174-0004, Japan \\ ${ }^{2}$ Tokyo Institute of Technology, Kanagawa, 226-8503, Japan
}

\begin{abstract}
Kasumi levees are a type of discontinuous levee system that was used in early-modern times of Japan, but few records remain of the hydraulic design of the levee construction. Results of numerical flow simulation are presented for the hydraulic functioning of the Kasumi levee system along the Kurobe River that flows on a steep alluvial fan. Historical records from the $19^{\text {th }}$ century to the present were used to simulate the flow through a levee system.. The computational results suggest that the flood control strategy was such that old river paths were utilized for temporary floodways and a portion of this diverted flow was returned to the main river channel through funnel-shaped levee openings located along the middle reach to prevent inundation of the alluvial fan.
\end{abstract}

\section{Introduction}

A variety of discontinuous levee systems, that are now typically called "kasumi (meaning haze) levees", were built from the 17 to mid $-19^{\text {th }}$ centuries to mitigate the impact of river flooding. The most common perception of the kasumi levee system is a series of funnelshaped levees opening upstream as shown in Fig. 1: Storm water, exceeding the river channel capacity, was spread backwards, reducing the river discharge, returning to the channel when the flood receded. According to Okuma [1], the design of these levees varied depending on the geographical and hydrological conditions with the major hydraulic function depending on the ground slope.

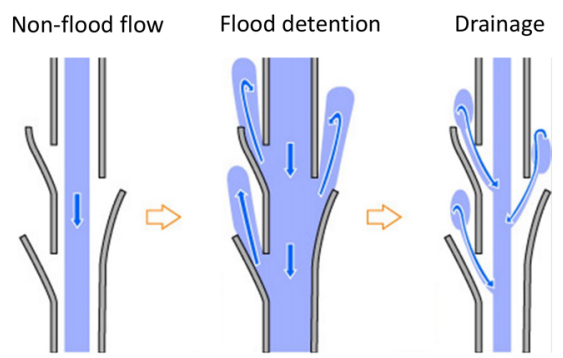

Fig. 1. Typical kasumi levee arrangement

1 Corresponding author: senoo-h@tokencon.co.jp 
In this study, hydraulic role of the discontinuous levee system constructed on the Kurobe Alluvial Fan in the $19^{\text {th }}$ century was studied by numerical flood simulation using shallow flow model on unstructured triangular grids [2], and the strategy of flood risk management on the alluvial fan in those days was discussed.

Due to the absence of historical topographical and hydrological data, the simulation parameters were determined from a combination of some $19^{\text {th }}$ century flood damage records, a levee map drawn at the end of $19^{\text {th }}$ century, flood hydrographs observed in the middle of $20^{\text {th }}$ century, modern river channel measurements and GIS elevation floodplain data.

\section{Study Site}

The Kurobe River flows down $85 \mathrm{~km}$ with an elevation drop of 3,000m, from the central mountains of Japan's Main Island to the Japan Sea. The large volume of sediment carried by the canyon river formed an alluvial fan with a radius of $13 \mathrm{~km}$, a top angle of $60^{\circ}$, and an average slope of $1 / 100$ at the downstream river reach (see Fig. 2).

Fig. $2 \mathrm{~b}$ shows a contour map of the alluvial fan in which the light blue bands represent the old river courses before the $19^{\text {th }}$ century. The contour lines are almost concentric except near the coast. The zone of transition from erosion to sedimentation is located at around the $50 \mathrm{~m}$ above sea level [3] and geological evidence suggest that the river channel moved during the recent geomorphic process.

In the early 19 th century, the branching streams were aligned into a single channel by constructing the levee system shown by the black lines in the Fig. $2 b$. The "K" suffix values indicate the distance from the river mouth in kilometers. This realignment of the channel caused the northeast coast to erode due to the absence of sediment supply and river delta to progressively move further out to the sea [4].
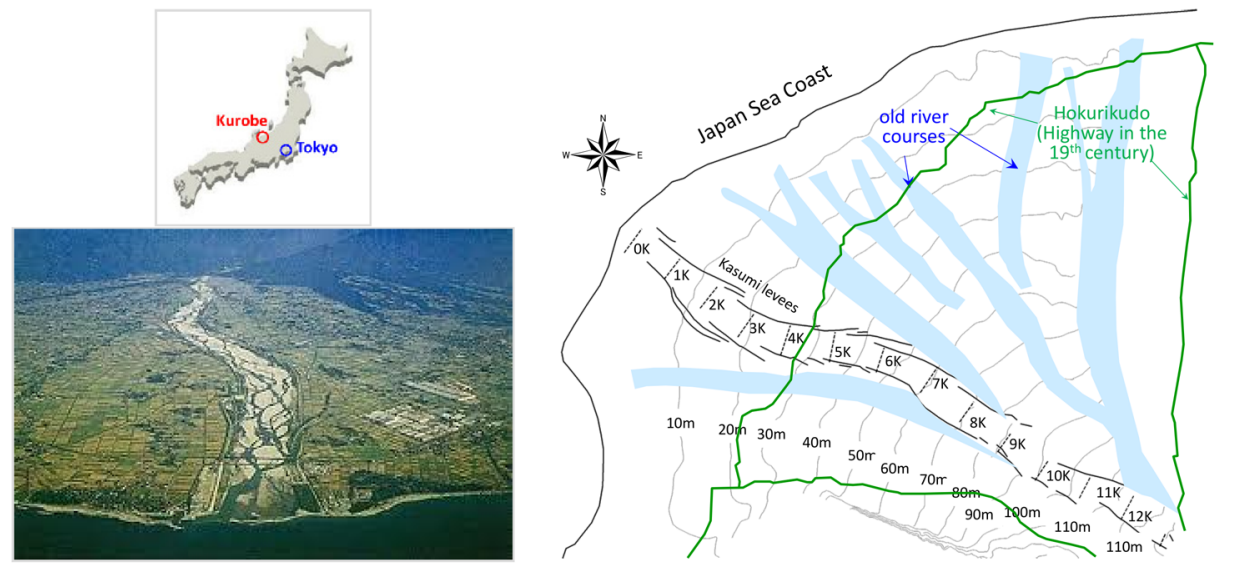

Fig. 2. Topography of Kurobe Alluvial Fan

Fig. 3 shows the longitudinal profiles of the river channel bed and the ground level of both banks measured from the present high-water level. The channel bed is lower than the nearby ground in the upstream reach, while higher in the downstream reach as a result of geomorphic dissection, which was magnified in the narrowly fixed river channel. By comparing Fig. 2 and Fig. 3, we can see an overall correlation between the levee arrangements and the ground level differences as follows: Levees were doubled or tripled in the downstream reach as typical kasumi levee arrangement where the channel bed is higher than the nearby ground ( $\mathrm{KP}<5$ at the left bank and $\mathrm{KP}<7$ at the right bank). On the other hand, the levees had wide openings in the upstream reach where the channel bed was not higher than the nearby ground. 


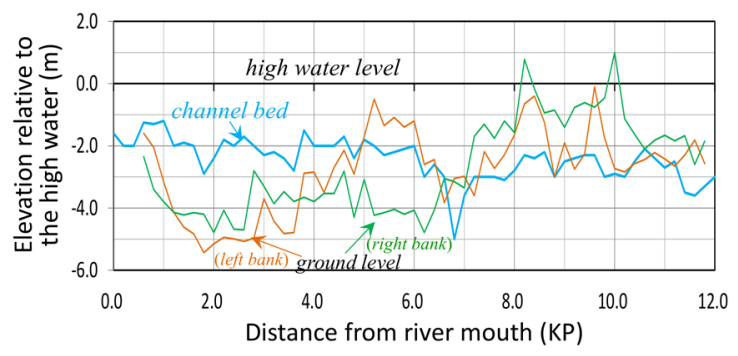

Fig. 3. Longitudinal bed profiles relative to the high water level

Fig. 4 shows the probability of annual maximum discharge for the last 56 years. The largest recorded discharge was $6,700 \mathrm{~m}^{3} / \mathrm{s}$ in 1969 that corresponds to a return period of about 100 years. According to a historical record, villages along the river were affected by river overflow ten times during the 68 years from 1828 to 1895 . The flood frequency corresponds to a $2,700 \mathrm{~m}^{3} / \mathrm{s}$ river discharge as indicated by green in the figure.

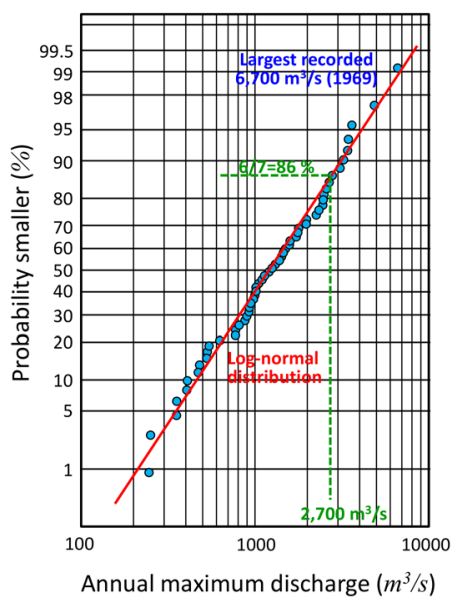

Fig. 4. Probability plot of annual maximum discharge

\section{Methodology}

\subsection{Numerical model}

A set of shallow water equations was adopted for the numerical simulation model.

$$
\begin{gathered}
\frac{\partial h}{\partial t}+\frac{\partial(U h)}{\partial x}+\frac{\partial(V h)}{\partial y}=0 \\
\frac{\partial(U h)}{\partial t}+\frac{\partial(U U h)}{\partial x}+\frac{\partial(U V h)}{\partial y} \\
=-g h \frac{\partial H}{\partial x}+\frac{\partial\left(h \tau_{U U}\right)}{\partial x}+\frac{\partial\left(h \tau_{U V}\right)}{\partial y}-\frac{\tau_{0}}{\rho} \frac{U}{\sqrt{U^{2}+V^{2}}} \\
\frac{\partial(V h)}{\partial t}+\frac{\partial(U V h)}{\partial x}+\frac{\partial(V V h)}{\partial y} \\
=-g h \frac{\partial H}{\partial y}+\frac{\partial\left(h \tau_{U V}\right)}{\partial x}+\frac{\partial\left(h \tau_{\tau V}\right)}{\partial y}-\frac{\tau_{0}}{\rho} \frac{V}{\sqrt{U^{2}+V^{2}}}
\end{gathered}
$$


where $(U, V)$ are the velocity components in $(x, y)$ coordinates, $h$ is the water depth, $H$ is the water surface level $(=h+$ ground level), $\rho$ is the water density, and $g$ is the gravitational acceleration. $\tau_{0}$ is the bed friction force, and $\tau_{U U}, \tau_{U V}$ and $\tau_{V V}$ are the horizontal shear stresses, which are expressed by the following equations:

$$
\begin{gathered}
\tau_{0}=\rho U_{f}^{2}=n^{2} \frac{\rho g\left(U^{2}+V^{2}\right)}{h^{1 / 3}} \\
\tau_{U U}=2 \varepsilon \frac{\partial U}{\partial x}-\frac{2}{3} k \quad \tau_{U V}=\varepsilon \frac{\partial U}{\partial y}+\varepsilon \frac{\partial V}{\partial x} \quad \tau_{V W}=2 \varepsilon \frac{\partial V}{\partial y}-\frac{2}{3} k \\
\varepsilon=\frac{1}{6} \kappa U_{f} h \quad k=2.07 U_{f}^{2}
\end{gathered}
$$

where $U_{f}$ is the friction velocity, $n$ is Manning's roughness coefficient, $\varepsilon$ is the vertically averaged eddy viscosity, $k$ is the turbulent kinetic energy, and $\kappa$ is the Karman constant.

The differential equations were converted to difference equations by the finite volume method on the unstructured triangular mesh system. The equation forms and solving process are described in Akoh et al. [2].

The flow rate over the banks was calculated by the formula presented by Honma [5]:

$$
q= \begin{cases}0.35 h_{1} \sqrt{2 g h_{1}} & \text { if } h_{2} / h_{1} \leq 2 / 3 \\ 0.91 h_{2} \sqrt{2 g\left(h_{1}-h_{2}\right)} & \text { otherwise }\end{cases}
$$

where $q$ is the flow rate over the unit length, and $h_{1}$ and $h_{2}$ are the water depths on the upstream and downstream sides, respectively.

\subsection{Calculation condition}

Because of the absence of data for the alluvial fan topography in the $19^{\text {th }}$ century, the GIS elevation data published in 2015 (grid size; $5 \mathrm{~m}$ ) were used for the numerical simulations. Local elevation changes due to the construction of roads and railways were removed by interpolation from surrounding elevation values. The Hokuriku-do (a $19^{\text {th }}$ century highway) indicated by green lines in Fig. 2 was assumed as a low embankment $60 \mathrm{~cm}$ higher than the surrounding ground.

Due to the high sediment load from the upstream canyons, the river channel bed is covered by a pattern of moving sand bars that continually propagate downstream (see the photograph in Fig. 2). The standard deviation from the transversely averaged bed elevation undulations is approximately $1 \mathrm{~m}$. In addition, the bed bathymetry is strongly affected, since 1960 , by the construction of a high dam in the upstream canyon as well as bed sediment excavation for construction aggregates. Therefore, the longitudinal profile of the transversely averaged bed topography, measured in 1963, was adopted for the simulations

Fig. 5 shows the design flood hydrograph, adopted in 1969 for the present river improvement works. Hydrographs used in the numerical simulation were simple magnifications of that shown in Fig. 5, uniformly scaled to reflect a peak discharge listed at the left side of the figure. The peak flow in Case 1 was just over the channel capacity (indicated by green in Fig. 4), and the other two cases were extraordinary floods that would cause significant damage along the river.

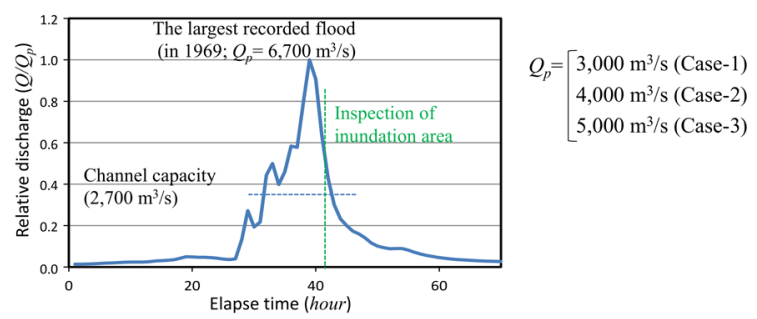

Fig. 5. Design flood hydrograph (1969) 


\section{Results and discussions}

\subsection{Results of numerical simulation}

Fig. 6 shows the inundation depth at the flood peak and the receding phase for the case of $Q_{p}=3,000 \mathrm{~m}^{3} / \mathrm{s}$. River water overflowed to the left-side floodplain through a levee opening around $9 \mathrm{~K}$ and flowed down the old river channel along the backside of levees (see Fig. 2). During the receding phase, a portion of the flood water returned to the river channel through levee openings located from $3 \mathrm{~K}$ to $5 \mathrm{~K}$.
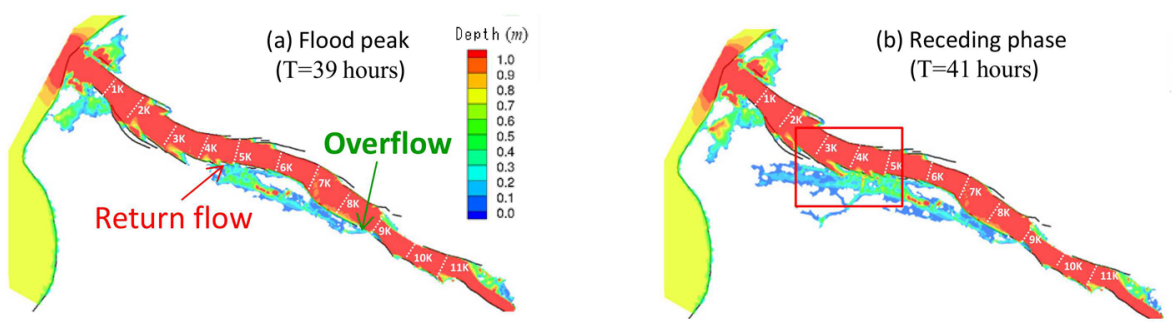

Fig. 6. Water depth (Case-1), at flood peak (left) and during the receding phase (right)

Fig. 7 (a) show the velocity vectors in the area indicated with the red rectangle in Fig. 6 (b). Fig. 7 (b) shows the hydrograph at the upstream boundary (blue), the rate of overflow through the levee opening at $9 \mathrm{~K}$ (green), and the rate of returning flow through the levee openings from $3 \mathrm{~K}$ to $5 \mathrm{~K}$ (red). The peak of returning flow had a time lag of two hours from the flood peak, when the river discharge was already receding.
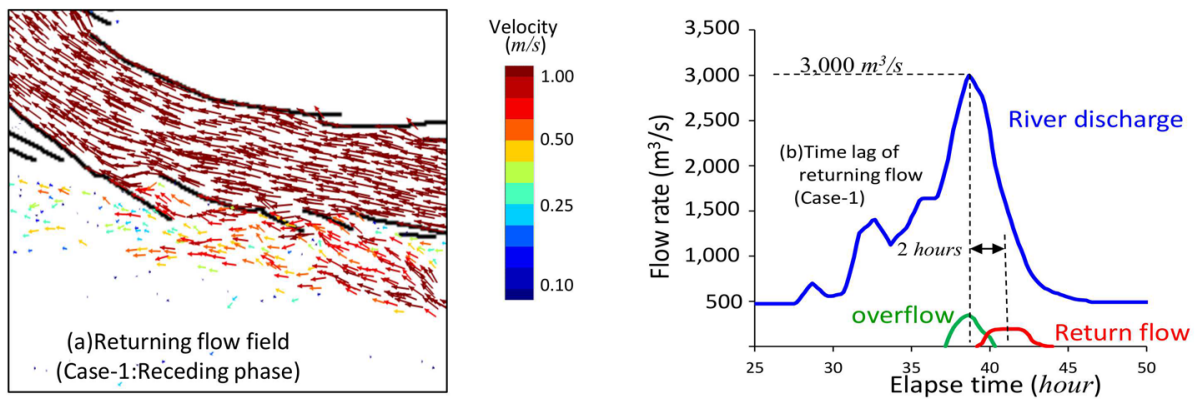

Fig. 7. Returning flow during the receding phase

Fig. 8 shows the course of flood flow estimated by Teramura [6] for the 1934 flood $\left(Q_{p}\right.$ $\left.\sim 3,000 \mathrm{~m}^{3} / \mathrm{s}\right)$. It shows the same tendency as the calculated flood flow: river water overflowed to the left-side floodplain around $9 \mathrm{~K}$, flowed along the levee backside, and partially returned to the river channel through the openings near $5 \mathrm{~K}$.

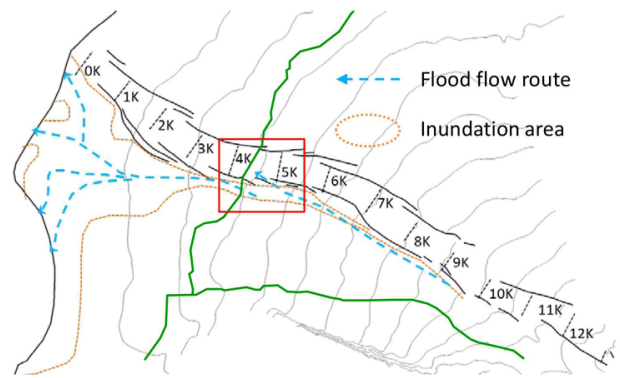

Fig. 8. Inundation record from 1934 (Teramura, [6]) 
Fig. 9 (a) shows the inundation depth at the receding phase obtained for $Q_{p}=5,000 \mathrm{~m}^{3} / \mathrm{s}$ and Fig. 9 (b) shows the velocity vectors in the area indicated with red rectangles in Fig. 9 (a). The flooding area was almost within the old river channel as for the case of $Q_{p}=3,000$ $\mathrm{m}^{3} / \mathrm{s}$, although the inundation volume became larger with increasing river discharge. The levee openings between the long doubled levees around $3 \mathrm{~K}$ did not drain the landside water, but the levees prevented overflow from the river channel to the flat lowland at the left bank side.
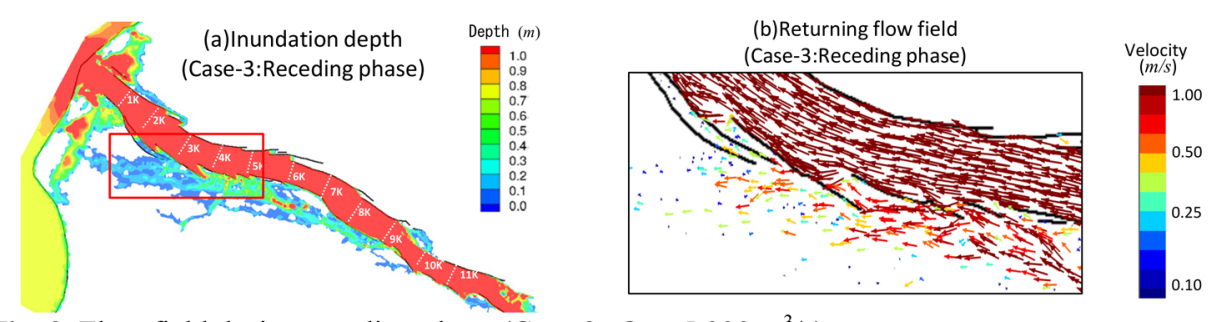

Fig. 9. Flow field during receding phase (Case- $3: Q_{p}=5,000 \mathrm{~m}^{3} / \mathrm{s}$ )

\subsection{Hydraulic function of right bank levees}

In the above-mentioned calculation, river overflow happened only to the left-side floodplain. However, this does not prove that the right-side floodplain was always safe from river overflow. As mentioned earlier, the channel bed is covered by multiple bars having large amplitude, which implies that levee overtopping could have occurred due to a channel bed rise near the right bank. The long, doubled levees below $7 \mathrm{KP}$ might be the most effective measure against river overflow to the old river channel.

An experiment was performed to examine the function of the right bank levee arrangement by inducing a river overflow to the right-side floodplain. The river channel bed was raised by $1 \mathrm{~m}$ to induce overflows on both sides of the channel. Three back levees of the doubled levee sections (red lines in Fig. 10) were removed to examine the flow field changes over the floodplain from the original levee arrangement.

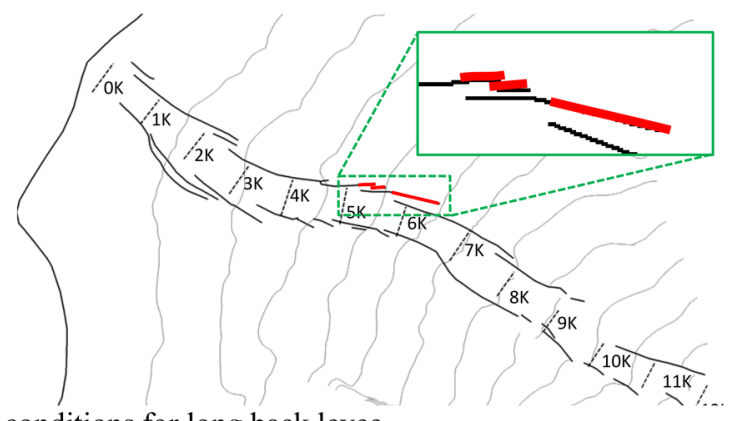

Fig. 10. Experimental conditions for long back levee

Fig. 11 shows the water depth and velocity field calculated for the original levee arrangement (Case-A) during the flood receding phase, and Fig. 12 shows those for the modified levee arrangement (Case-B). River water overtopped the right bank levees around $8 \mathrm{~K}$, and flowed down the old river channel. In Case-A for the original levee alignment, the long back levee located around $6 \mathrm{~K}$ interrupted the flood flow and returned a portion of the flow to the main channel. As a result, the two villages located at a slightly higher elevation area were not inundated, while the villages were inundated by a strong current in Case-B. 

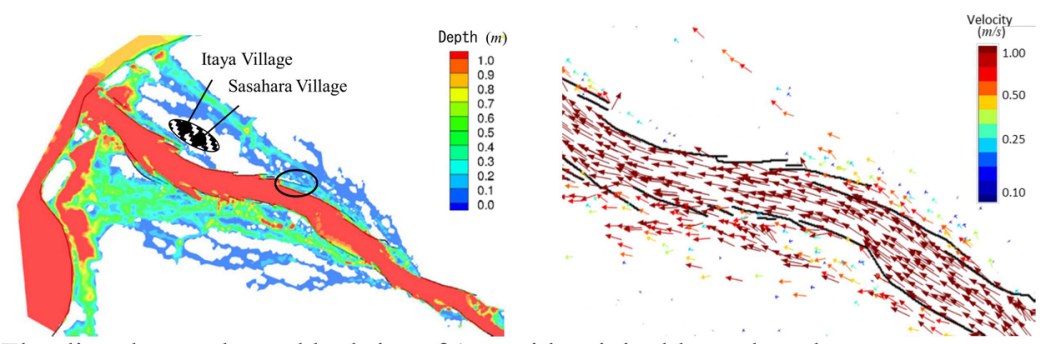

Fig. 11. Flooding due to channel bed rise of $1 \mathrm{~m}$ with original levee lengths
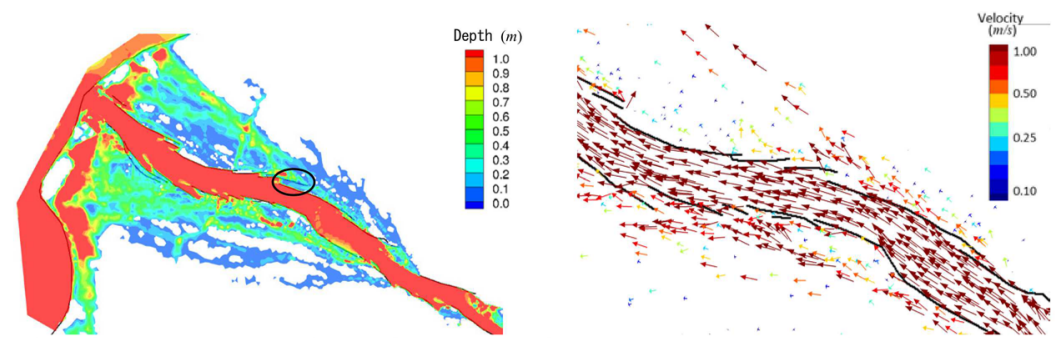

Fig. 12. Flooding due to channel bed rise of $1 \mathrm{~m}$ with three levees removed.

\subsection{Strategy of flood risk management in the early 19th century}

The numerical results discussed above can be used to formulate the flood risk management strategy on the Kurobe Alluvial Fan in the early $19^{\text {th }}$ century as follows (see Fig. 13): Civil engineers utilized old river channels as temporary floodways and located levee openings to induce flow divergence as indicated with green arrows in the figure because the levee height of $3 \mathrm{~m}$ could not confine the large volume of runoff water in the river channel. When the overflow rate exceeded the capacity of the old river channels, long back levees guided the excess water to return to the main channel as indicated with red arrows in Fig. 13. In addition, because the flood duration of Kurobe River was short (see Fig. 5), the floodwater in the old river channel could be drained to the main channel at the flood receding phase through the funnel-shaped levee openings located in the middle reach of the river.

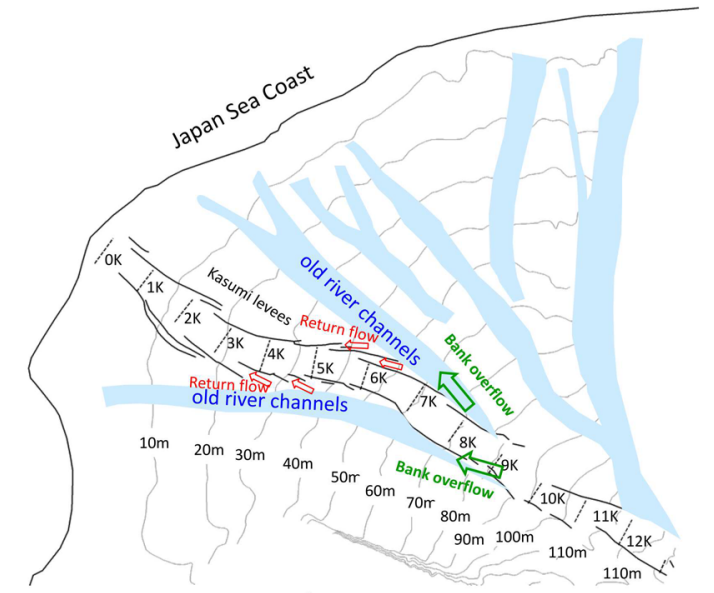

Fig. 13. Flood control strategy for the early $19^{\text {th }}$ century 


\section{Conclusions}

The exact topographical and hydrological conditions when the system was established were not available for numerical simulation, and the results and discussions thus contain some uncertainties, but the following conclusions may be obtained:

(1) During periods of floods larger the channel capacity, excess water overflowed to the left side floodplain. The floodwater flowed down the old river channel without spreading widely and a portion of the flow returned to the main river channel through funnel-shaped levee openings located around $5 \mathrm{~K}$. This agrees with the flood record in 1934 presented by Teramura [6].

(2) Because the computations with the transversely averaged river bed elevation did not indicate a river overflow to the right-side floodplain, an experiment was conducted with a $1 \mathrm{~m}$ river bed rise to examine the hydraulic function of the kasumi levee alignment on the right bank. The result shows that the floodwater flowed into the right-side old river channel from $8 \mathrm{~K}$, and that a portion of the flood flow returned to the main river channel guided by the long back levees and funnel-shaped openings around $6 \mathrm{~K}$, thereby protecting the downstream villages from inundation.

(3) The results suggest that the $19^{\text {th }}$ century flood control strategy for the alluvial fan was as follows. During large rain runoff, the old river channels were utilized as temporary floodways by locating levee openings at the channel heads. In order to prevent inundation from spreading on the alluvial fan, funnel-shaped levee openings were located to return a portion of the flood flow exceeding the old channel capacity to the main river channel.

Acknowledgement. Authors would like to thank Professor Jorg Imberger for helping to edit the manuscript.

\section{References}

1. T. Okuma, Hist. Stud. Civ. Eng., 7, 259 - 266 (1987) (in Japanese)

2. R. Akoh, T. Ishikawa, T. Kojima, M. Tomaru and S. Maeno, Nat. Hazards Earth Syst. Sci., 17, 1871 - 1883, (2017)

3. T. Ishikawa and H. Yamamoto: Proceedings of JSCE, 381, 35-43 (1987) (in Japanese)

4. S. Fujii, Earth Sci., 78, 11 -20 (1965) (in Japanese)

5. H. Honma, J. JSCE, 26, 635 - 645 (1940) (in Japanese)

6. A. Teramura, Hist. Stud. Civ. Eng., 28, 119 - 124 (2008) (in Japanese) 